\title{
RESISTENCIA DE SOJA A INSETOS. II. TESTE DE LIVRE ESCOLHA ENTRE A LINHAGEM IAC 73/228 E O CULTIVAR PARANÁ, INFESTADOS POR NEZARA VIRIDULA (L.) EM TELADO (1)
}

CARLOS JORGE ROSSETTO, ANDRẼ IUTZ LOURENC̣ÃO (2), Seção de Entomologia Fitotécnica, MANOEL ALBINO COELHO DE MIRANDA (2), Seção ae Leguminosas, e TOSHIO IGUE, Seçāo de Técnica Experimental e Cálculo, Instituto Agronômico.

\section{RESUMO}

A linhagem de soja IAC $73 / 228$ foi comparada com o cultivar Paraná, em condições de telado e com infestação artificial de Nezara viridula (L.) (Hemiptera, Pentatomidae). As plantas foram cultivadas diretamente no solo do telado. Utilizou-se um delineamento em blocos ao acaso com dois tratamentos e trinta repetições, sendo a parcela de uma planta individual. Năo houve diferença no número de percevejos observados infestando os dois tratamentos. O número de vagens planas (não granadas) resultantes do dano causado pelos insetos, também nāo diferiu nos dois tratamentos. O número total de vagens da linhagem IAC 73/228 foi em média 291 e, o do 'Paraná', 100. O número de vagens cheias (com grãos desenvolvidos) e o peso de grãos comerciais colhidos da linhagem IAC $73 / 228$ foram maiores que os do 'Paraná'. Compa. rando as produções em peso dos dois materiais, com infestação artificial do inseto e sem infestação em telado contiguo, observou-se que a linhagem não sofreu nenhuma perda na sua produção devida à infestação do inseto, enquanto o cultivar sofreu $67,5 \%$ de quebra na produção. Por ocasião da colheita, todas as plantas do 'Paraná' apresentavam o sintoma de retenção foliar, conhecido por "soja louca", contra apenas quatro plantas $(13,3 \%)$ da linhagem IAC $73 / 228$. Concluiu-se que os quatro critérios mais práticos para discriminar materiais resistentes de suscetíveis em condiçoses de alto nível de infestação foram: produção em peso de grãos, porcentagem de plantas com retenção foliar, índice de dano de vagens da regiăo mediana da planta e porcentagem de grãos sadios.

(1) Recebido para publicaçăo a 29 de novembro de 1982.

(2) Bolsista do CNPq. 


\section{INTRODUÇÃO}

Os percevejos pentatomídeos Nezara viridula (L.), Piezodorus guildinii (Westwood) e Euchistus heros (Fabricius), constituem o principal grupo de pragas da soja no Estado de São Paulo. Não fosse sua presença, muito pouco inseticida seria usado na cultura da soja neste Estado.

Outras pragas da soja, como os insetos mastigadores, besourinhos e lagartas, requerem menos aplicações de inseticidas para seu controle em São Paulo, em primeiro lugar porque as populações de besourinhos têm pequena capacidade de corte e as plantas de soja em geral toleram alta porcentagem de corte de folhagem, sem sofrer dano (RAMIRO \& OLIVEIRA, 6). Em segundo lugar, porque o crescimento das populações de lagartas, em geral, é acompanhado pelo aumento de incidência de doenças causadas por microorganismos entomopatogênicos que dizimam as populações de lagartas, antes que elas atinjam o nível de dano econômico, estabelecendo um equilíbrio natural das populações.

Os percevejos pentatomídeos têm suas posturas muito parasitadas por microimenópteros e os adultos são parasitados por dípteros taquinídeos. Na ausência de inseticidas, as populações de percevejos entram em equilíbrio. $O$ uso de inseticida para controle de percevejos pentatomídeos em soja não se compatibiliza com o controle biológico natural feito pelos inimigos naturais, em geral presentes nessa cultura.

A não-utilização de inseticidas para controle de percevejos em soja pode representar, na prática, portanto, uma eliminação quase total de seu emprego na cultura da soja no Estado de São Paulo. Essa é apenas uma hipótese, mas tem sólido fundamento e sua validade deve ser testada. Se for válida, esta tese poderá representar um avanço tecnológico expressivo para a cultura da soja no Brasil.

Outrossim, os inseticidas, numa estratégia ideal de controle, deveriam ser empregados apenas contra populações altas de insetos, já que, nessas condições, matariam mais insetos por metro quadrado e por quilograma de princípio ativo utilizado, tornando seu uso mais eficiente.

Uma população de percevejos de dois adultos por metro linear de soja, no estádio de frutificação, é um nível de infestação que atualmente causa dano econômico, ou seja, um nível que requer o uso de inseticida para controle (GAZZONI, 2). Tal uso, todavia, para controlar populações pouco densas, como dois insetos por metro linear, não é uma estratégia ideal de controle, pois, para controlar percevejos, mata os insetos úteis e provoca desequilíbrio biológico, favorecendo um ressurgimento de uma população maior dos próprios percevejos ou 
de lagartas. O ideal seria substituir os inseticidas para controlar os percevejos em soja por uma tecnologia alternativa. Isso possibilitaria uma ação mais eficiente do controle biológico natural.

A melhor alternativa para substituí-los no controle de percevejos na cultura da soja, em futuro próximo, é a obtenção de variedades resistentes. As Seções de Entomologia Fitotécnica e Leguminosas do Instituto Agronômico, Campinas, vêm trabalhando com esse objetivo desde 1976. Inicialmente, foi feita uma avaliação de campo, da possibilidade de utilizar a variedade IAC $73 / 228$ como fonte de resistência aos percevejos. Esse estudo (MIRANDA et alii, 5) demonstrou que a IAC $73 / 228$ era significativamente menos danificada que as variedades comerciais, especialmente em relação ao cultivar Paraná, muito suscetível.

No presente trabalho, o comportamento desses dois materiais foi estudado em condições de telado com e sem infestação artificial de Nezara viridula (L.).

\section{MATERIAL E MÉTODOS}

A linhagem IAC $73 / 228$ é de ciclo médio, enquanto o cultivar Paraná é precoce. Por essa razão, a linhagem foi plantada a 16 de janeiro e, o cultivar, a 25 de janeiro de 1980, para obter coincidência de frutificação. O ensaio obedeceu a um delineamento de blocos completos casualizados com dois tratamentos e trinta repetições. Plantaram-se cinco sementes por cova e, após o desbaste, a parcela foi constituída por uma planta individual. O espaçamento foi $1 \mathrm{~m}$ por $0,50 \mathrm{~m}$. Foram instalados dois experimentos, da forma descrita, em dois telados contíguos.

Um dos experimentos foi artificialmente infestado com adultos de N. viridula, desde 4 de março de 1980 , quando as plantas estavam na fase de florescimento (R2), até 8 de abril, quando estavam na fase de enchimento de grãos (R5) e de grãos cheios (R6), segundo a classificação de FEHR \& CAVINESS (1). Setecentos adultos foram liberados no interior de um telado, enquanto o outro permaneceu sem infestação até a colheita.

A 26 de março e 17 de abril de 1980, quando as plantas se encontravam nas fases R5 e R6 respectivamente, foram feitas avaliações do número de adultos de $\mathbf{N}$. viridula infestando as plantas. Contou-se o número de adultos observados em cada planta durante um tempo padrão de dez segundos, tempo suficiente para fazer uma observação rápida e completa de uma planta. 
A 10 de junho de 1982, os dois experimentos foram colhidos, avaliando-se o peso da produção de grãos de ambos e eliminando-se os grãos danificados, sem valor comercial. No experimento infestado por percevejos, o número total de vagens foi contado, retirando-se uma amostra de dez vagens do topo e outra de quinze vagens da região mediana da planta. Essas vagens foram classificadas em cheias, quando todas as lojas apresentavam aspecto normal de grãos desenvolvidos; chatas, quando todas as lojas apresentavam-se sem grãos desenvolvidos, e intermediárias, quando pelo menos uma loja estava achatada e outra estava normalmente cheia.

Com base na idéia de índice de dano de grãos proposta por GILMAN et alii (3), foi desenvolvido um índice de dano de vagens (IDV) expresso pela fórmula:

IDV $=\%$ vagens intermediárias $+2(\%$ vagens chatas $), a$ qual resulta da simplificação da seguinte:

IDV $=0$ ( $\%$ vagens cheias $)+1$ ( $\%$ vagens intermediárias $)$ +2 ( $\%$ vagens chatas).

Os pesos relativos 0,1 e 2 foram escolhidos, assumindo-se um relacionamento linear entre tipo de vagem e dano. Uma vagem cheia em geral não sofreu dano: por isso, seu peso de dano relativo foi considerado 0. Uma vagem intermediária sofreu, em média, cerca de metade do dano de uma vagem chata: essas receberam, respectivamente, pesos 1 e 2 .

Após avaliação, as vagens foram abertas e os grãos, classificados em quatro categorias já descritas anteriormente (MIRANDA et alii, 5) : 1: sem dano; 2: dano leve, apenas punctura sem deformação; 3 : deformação moderada; 4 : grão pequeno muito deformado. Calculou-se um índice de dano de grãos idêntico ao proposto por GILMAN et alii (3) com a seguinte fórmula:

IDG $=0$ ( \% de grãos sem dano $)+1$ ( \% de grãos com dano leve $)+2(\%$ de grãos com dano moderado $)+3$ (\% de grãos com dano severo)

ou simplificando-se :

IDG $=\%$ de grãos com dano leve $+2(\%$ de grãos com dano moderado $)+3$ (\% de grãos com dano severo).

Obteve-se um índice de dano de grãos para a amostra do topo da planta (IDGT) e outro para a parte mediana (IDGM).

Para fins de análise estatística, o número de adultos observados por planta foi transformado em $\log (\mathrm{x}+1)$. As porcentagens de grãos do tipo 1, 2, 3 e 4, bem como as porcentagens das três categorias de 
vagens, foram transformadas em arco seno $V \bar{x}$. Para análise, os números totais de vagens dos três tipos foram transformados em $\sqrt{\mathrm{x}}$. O peso de grãos e os índices de dano IDV e IDG foram analisados diretamente sem transformações.

\section{RESULTADOS E DISCUSSÃO}

Os resultados de contagens de percevejos nas variedades estão sumariados na figura 1.

$\mathrm{Na}$ primeira observação, feita quando a soja estava na fase R5, a linhagem IAC 73/228 apresentou média de 0,90 adulto por planta e o'Paraná', 1,07. Na segunda observação, em R6, a linhagem apresentou média de 1,43 adulto por planta e o cultivar, 1,20. Não houve diferença significativa entre o número de percevejos adultos observados no tempo padrão de dez segundos, entre os dois tratamentos.

A figura 2 mostra que não houve diferença significativa no número de vagens chatas (totalmente danificadas pelos insetos), entre os dois tratamentos, e que a linhagem IAC 73/228 apresentou uma média de 248 vagens sadias por planta, enquanto o cultivar Paraná teve uma média de 68,8. O inseto atacou maior número de lojas na IAC 73/228, mas como ela tem um número muito maior de vagens, sobrou-lhe um núinero maior de vagens sadias. Isso indica uma resistência do tipo tolerância, confirmando a conclusão de ROSSETTO et alii (7). Confirma também a conclusão de LINK \& ESTEFANEL (4) que, quanto maior o número de legumes por planta, menor a porcentagem de grãos danificados.

A figura 3 sumaria os resultados de produção em peso das duas variedades, com e sem infestação de $\mathbf{N}$. viridula.

O cultivar teve sua produção média por planta reduzida de $36,46 \mathrm{~g}$ para $11,85 \mathrm{~g}$, ou seja, uma redução de $67,5 \%$ na produção. A linhagem aumentou sua produção de $73,37 \mathrm{~g}$, por planta, para $75,89 \mathrm{~g}$, ou seja, 3,4\% a mais. Pode-se afirmar que a IAC 73/228 não sofreu quebra na produção devida à infestação do percevejo.

A tolerância da linhagem IAC $73 / 228$, já referida por ROSSETTO et alii (7), fica mais evidente, pois, apesar de ter, em média, 13,6 vagens totalmente danificadas e 29,4 vagens parcialmente danificadas por planta, ela não sofreu redução em peso na produção.

Os dados anteriormente discutidos sugerem que a linhagem IAC 73/228 não apresenta o tipo de resistência de não-preferência para alimentação do inseto, e, sim, o tipo de resistência denominado tolerância.

Pela figura 1, vê-se que, em média, a infestação foi 0,98 inseto por planta em R5 e 1,31 em R6. Pode-se considerar, portanto, que neste 


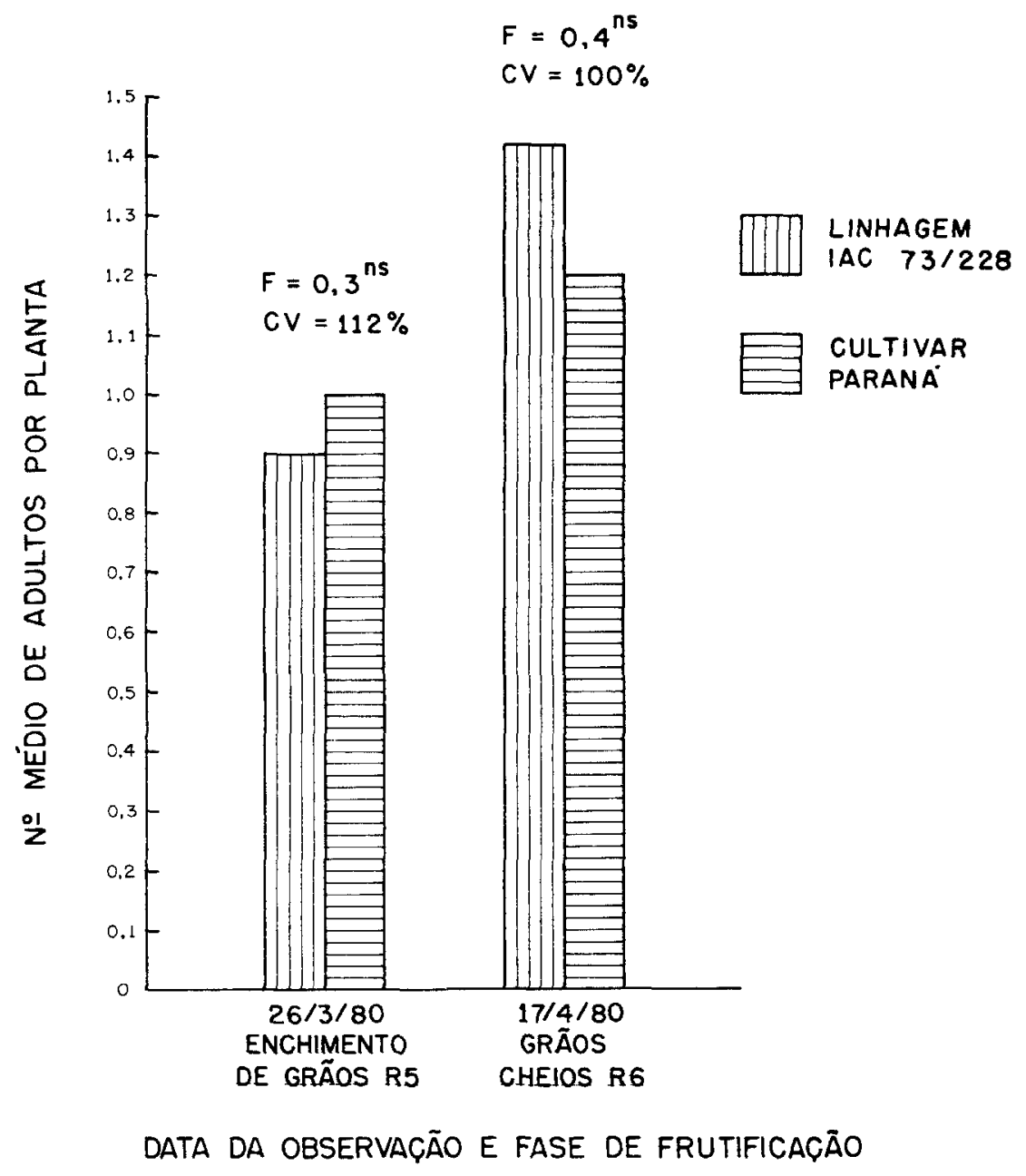

FIGURA 1 - Número médio de adultos de Nezara viridula (L.) observados por planta, durante dez segundos de observação, em duas variedades de soja no interior de um telado, com livre chance de escolha. Campinas, 1980. 


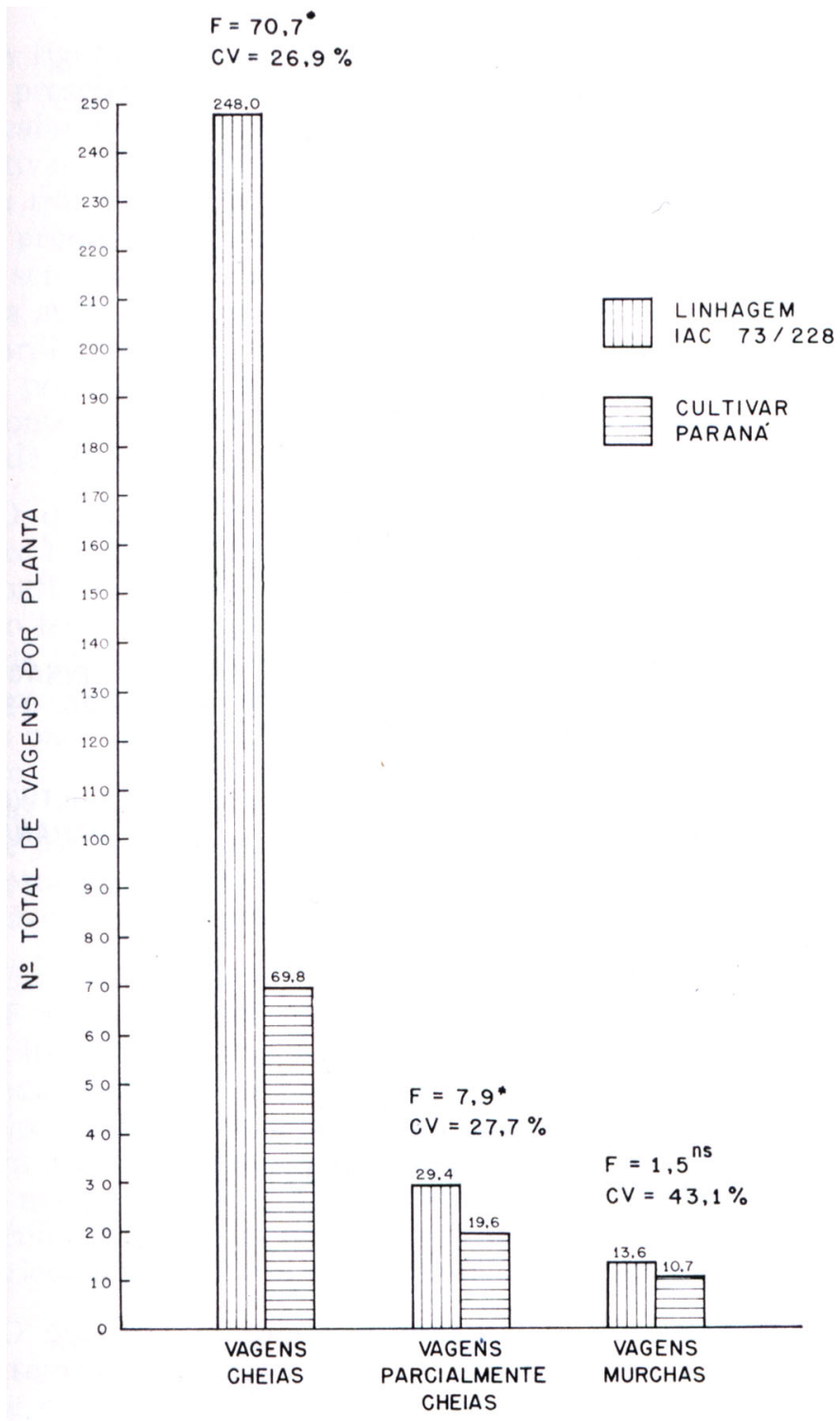

FIGURA 2 - Média por planta do número total de vagens de três tipos diferentes - sadias, parcialmente danificadas e totalmente danificadas - por Nezara viridula (L.) em duas variedades de soja. Campinas, 1980. 


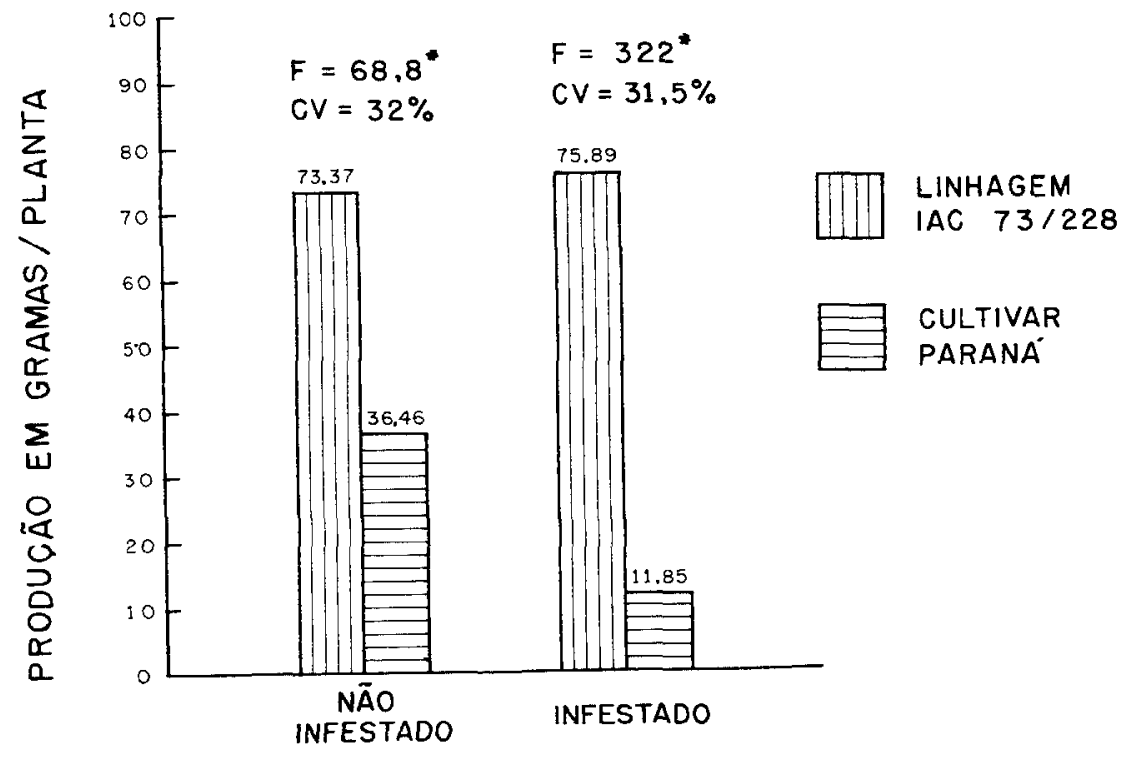

FIGURA 3 - Peso médio de grãos, em gramas por planta, de duas variedades de soja, cultivadas em dois telados contíguos, sendo um infestado por Nezara viridula (L.) e, outro, não infestado. Campinas, 1980. 
experimento o nível médio de infestação de $\mathbf{N}$. viridula, na fase reprodutiva da planta, foi aproximadamente um inseto por planta.

A figura 3 mostra que a diferença na produção varietal ficou maior na presença dos percevejos, com o teste $F$ para tratamentos atingindo o valor de 322 e a linhagem produzindo quase sete vezes mais que o cultivar. Na ausência de infestação dos percevejos, embora o valor de $F$ para tratamentos seja menor, ainda assim é alto $(F=68,8)$, e a linhagem produziu o dobro do cultivar. Isso indica que a IAC $73 / 228$, além de ser tolerante ao ataque de percevejos, foi mais produtiva, mesmo na ausência da praga, nas condições deste experimento, isto é, plantio tardio no interior de um telado com espaçamento largo. Essa linhagem, portanto, dentro de um programa de melhoramento de soja, poderá contribuir com sua tolerância a percevejos e também com aumento de produtividade mediante o aumento do número de vagens.

O quadro 1 sumaria os resultados de dano nas vagens. As vagens do topo foram mais danificadas que as vagens do meio da planta, confirmando observação anterior de MIRANDA et alii (5). Os valores do teste $\mathrm{F}$ foram maiores para as amostras retiradas da parte mediana da planta, indicando que, em condições de infestação artificial, que confere alto nível de população do inseto, essa é a melhor região da pianta para distinguir as variedades resistentes das suscetíveis. Em geral, com infestação alta, as vagens do topo das plantas ficam muito danificadas, mesmo na variedade resistente, o que explica os menores valores de $\mathrm{F}$ obtidos para essa região. É possível que, em condiçōes de baixa infestação, o topo da planta seja melhor ou igual ao meio para discriminar as variedades quanto à sua resistência a percevejos.

$O$ índice de dano de vagens no meio da planta apresentou um valor de F maior e o coeficiente de variação menor que as porcentagens das três categorias de vagens (chatas, intermediárias e cheias) analisadas individualmente, devendo ser preferido para discriminar variedades em relação a percevejos. Há necessidade de comparar a eficiência do IDVM com a da porcentagem de lojas chatas ou cheias, o que não pode ser feito neste trabalho. Ambos podem ser rapidamente obtidos em campo, sendo prática sua utilização como um dos critérios para discriminar variedades quanto à sua resistência a percevejos.

O quadro 2 sumaria os resultados dos grãos amostrados. De maneira semelhante às vagens, os grãos do topo foram mais danificados que os do meio da planta; todavia, o valor do teste $F$ para o índice de dano de grãos no meio foi menor que o valor do teste $F$ para a porcentagem de grãos sem dano. Considerando que é menos trabalhoso obter a porcentagem de grãos sadios que o IDGM, a utilização do índice de dano de grãos não se justifica, sendo mais vantajoso o uso da porcentagem de grãos sadios como critério para discriminar variedades para resistência a percevejos. 


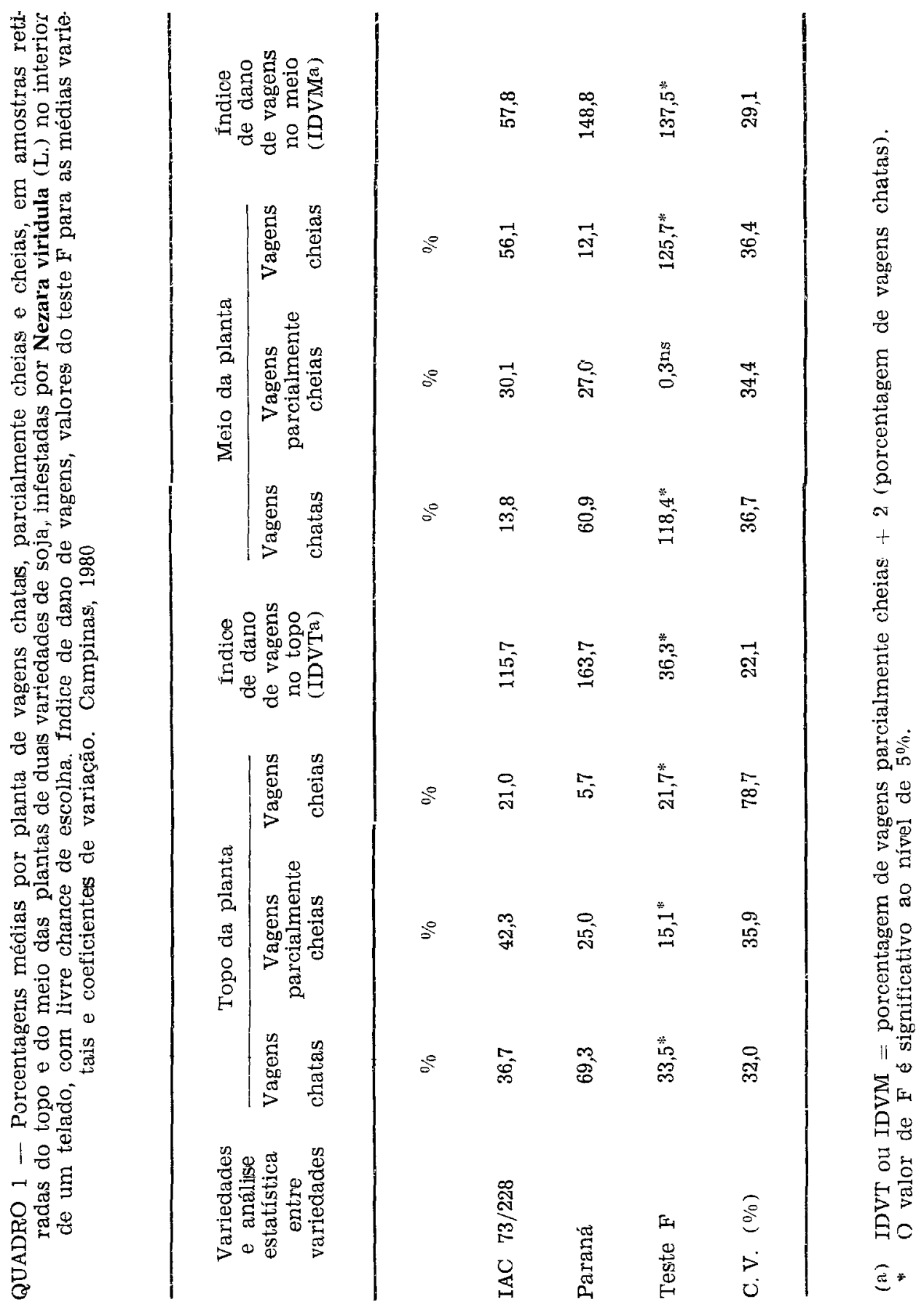




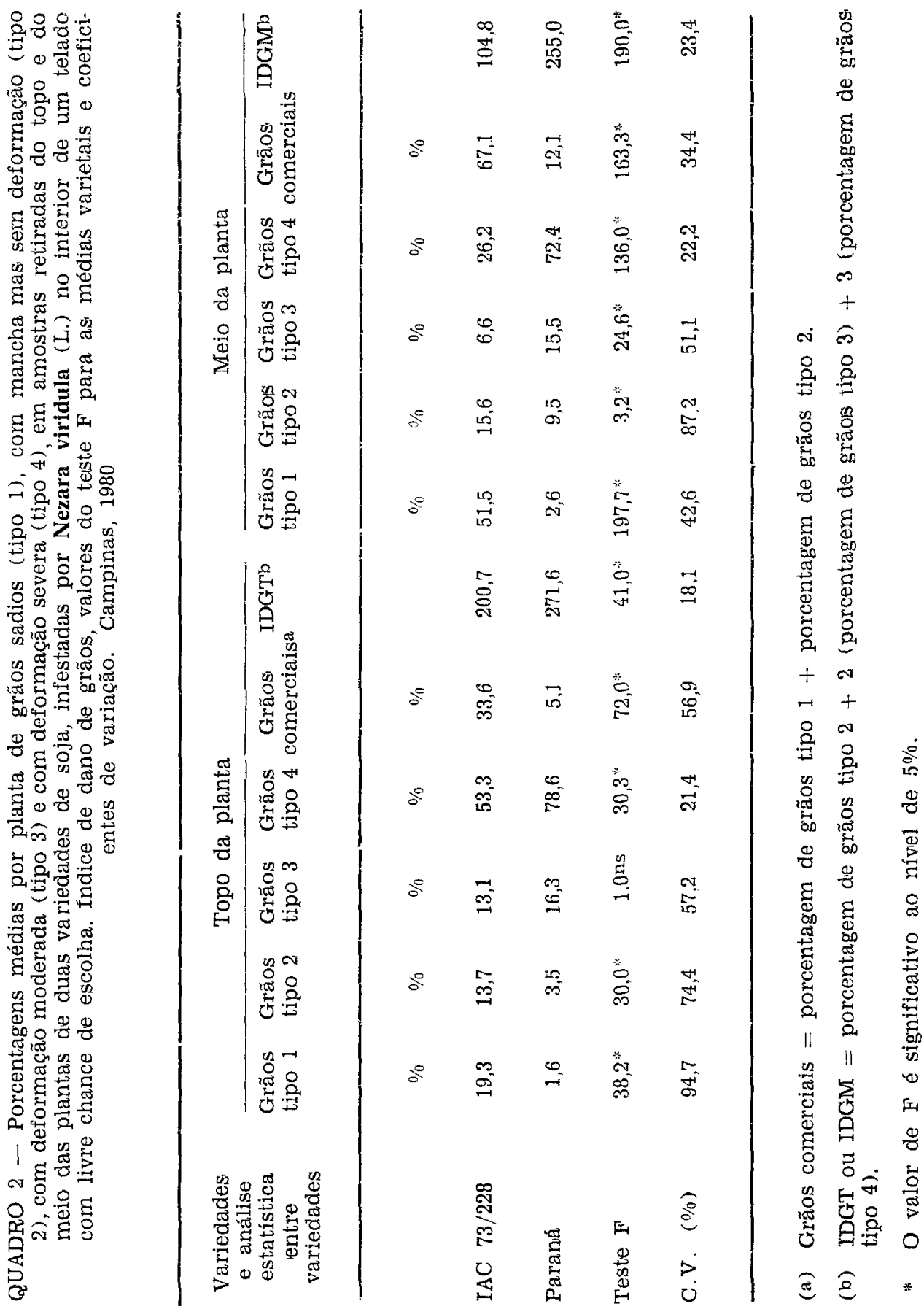


O dano nas vagens está correlacionado com o dano nos grãos. Essa correlação foi estimada, usando-se os índices de dano de vagens (IDV) e índices de dano de grãos (IDG). A correlação entre o IDV e o IDG para o topo foi $\mathrm{r}^{2}=0,89$ e, para a região mediana, $\mathrm{r}^{2}=0,96$. As equações de regressão obtidas foram IDGT $=64+1,23$ IDVT, $\mathrm{e}$ IDGM $=23+1,52$ IDVM.

Com relação à retenção foliar, foi observado, por ocasião da colheita, que $100 \%$ das plantas do cultivar apresentavam o sintoma conhecido por "soja louca", e a linhagem tinha $14,8 \%$ de plantas com este sintoma, $63 \%$ de plantas com maturação normal e $22,2 \%$ de plantas intermediárias.

Para selecionar variedades de soja resistentes a percevejos em condiçōes de infestação artificial, os quatro critérios mais indicados foram: peso de grãos comerciais, porcentagem de plantas com retenção foliar, índice de dano de vagens no meio da planta (IDVM) e porcentagem de grãos sadios.

\section{SUMMARY}

\section{RESISTANCE OF SOYBEAN TO INSECTS. II. FREE CHOICE TEST BETWEEN THE LINE IAC 73/228 AND THE CULTIVAR PARANÁ INFESTED BY NEZARA VIRIDULA (L.) UNDER SCREEN CAGE}

A free choice type experiment was made, with two treatments (line IAC $73 / 228$ and cultivar Paraná) and thirty replications, inside a screen cage with artificial infestation of Nezara viridula (L.) (Hemiptera : Pentatomidae). The level of infestation used in this experiment was, approximately, 1 adult per plant during the reproductive phase of the plant. There was no significant difference in the number of adults infesting both treatments. The number of damaged pods was also not significantly different in both treatments. However, the number of sound pods was 3.6 times grater in the line IAC $73 / 228$, since this line had a total number of pods of 291 per plant, in average, whereas the cultivar Paraná had 160 , and out of this total, the line IAC $73 / 228$ had, in average, 248 sound pods per plant whereas the cultivar Paraná had only 68.8. The mean yield obtained in the screen cage infested by the insect, was compared with the one obtained in an uninfested screen cage set beside it: under infestation, the line IAC 73/228 yielded about 7 times more than Paranta and in the absence of infestation, yielded twice as much. The cultivar Paranta had a decrease in yield of $67.5 \%$, due to the infestation, whereas the line IAC $73 / 228$ had an increase in yield of $3.4 \%$. The line IAC $73 / 228$ showed a good level of tolerance to Nezara viridula, and it was more productive than the cultivar Paraná even in the absence of infestation under the experimental conditions of screen cage, late plating and wide spacing between plants. Pod samples taken at the top and middle part of the plants showed greater damage at the top. The values of the $F$ test for treatments were greater for samples taken from the middle part of the plants. A damage index for pods was calculated as: IDP $=\%$ of intermediate pods $+2(\%$ of flattened pods $)$. The values of the F test between treatments using the IDP, for both regions, the top and the middle part of plants, were greater than the $F$ values obtained using the percentages of sound or damage pods. A similar damage index for the grains has also been proposed by GILMAN et alii, and is calculated with the 
formula: IDG $=0$ ( $\%$ of sound grains $)+1(\%$ of grains with light damage $+2(\%$ of grains with moderate shrunking) $+3(\%$ of grains with severe shrunking). The values of the $F$ test between treatments were, however, greater for the percentage of sound grains than for the IDG. All the plants of tie cuitivar Paraná remained green at harvest time, showing foliar retention called in Brazil "crazy soybean". Only $14.8 \%$ of the plants of the IAC 73/228 exhibited this sympton. Based on the above results, the authors recommended for criteria for soybean selection for resistance to stink bugs, under conditions of severe infestation: 1: the index of pod damage obtained from a sample taken from the middle part of the plants; 2: the percentage of sound grains obtained from the same sample;

3: the percentage of plants with foliar retention at havest time; and 4: yiela.

\section{REFERENCIAS BIBLIOGRÁFICAS}

L. FEHR, W. R. \& CAVINESS, C. E. Stages of soybean development. Iowa. State Univensity. Cooperative Extension Service, 1977. 12p. (Special Report, 80)

2. GAZZONI, D. L. Insetos, pragas e seu controle. In: MIYASAKA, S. \& MEDINA, J. C., ed. A soja no Brasil. Campinas, ITAL, 1981. p.569-593.

?. GILMAN, D. F.; MCPHERSON, R. M.; NEWSOM, L. D.; HERZOG, D. C.; WILLIAMS, C. Resistance in soybeanis to the Southern Green Stink Bug. Crop Science, $22(3): 573-576,1982$.

1. LINK, D. \& ESTEFANEL, V. Influência do nümero de sementes por legume e de legumes por planta sobre o nivel de dano de pentatomideos em soja. Revista do Centro de Ciências Rurais, Santa Maria, 12(2-3):109-113, 1982.

5. IMIRANDA, M. A. C. de; ROSSETTO, C. J.; ROSSETTO, D.; BRAGA, N. R.; MASCARENFAS, H. A. A.; TEIXEIRA, J. P. F.; MASSARIOL, A. Resistência de soja a Nezara viridula e Piezodorus guildinii em condições de campo. Bragantia, Campinas, 38:181-188, 1979.

6. PRIIRO, Z. A. \& OLIVEIRA, D. de A. Influência da desfolhação artificial na produtividade da cultura da soja. O Biológico, São Paulo, 41(4):97-104, 1975.

7 ROSSETTO C. J.; LOURENÇÃO, A. L.; IGUE, T.; MIRANDA, M. A. C. de. Picadas de alimentação de Nezara viridula em cultivares e linhagens de soja de diferentes graus de suscetibilidade. Bragantia, Campinas, 40:109. $114,1981$. 